\title{
Detección molecular de leptospiras patógenas en roedores sinantrópicos y silvestres capturados en Yucatán, México
}

\author{
Marco Torres-Castro', Bayron Cruz-Camargo', Rodrigo Medina-Pinto², Bibiana Reyes-Hernández', \\ Carlos Moguel-Lehmer ${ }^{3}$, Rolando Medina ${ }^{4}$, José Ortiz-Esquivel2, William Arcila-Fuentes ${ }^{2}$, Armando \\ López-Ávila1, Henry Noh-Pech¹, Alonso Panti-May5 ${ }^{5}$, Iván Rodríguez-Vivas², Fernando I. Puerto ${ }^{1}$ \\ 1 Laboratorio de Enfermedades Emergentes y Reemergentes, Centro de Investigaciones Regionales "Dr. Hideyo \\ Noguchi", Universidad Autónoma de Yucatán, Mérida, México \\ 2 Departamento de Salud Animal y Medicina Preventiva, Campus de Ciencias Biológicas y Agropecuarias, \\ Universidad Autónoma de Yucatán, Mérida, México \\ 3 Proyecto "Savia", Secretaría de Investigación, Innovación y Educación Superior, Mérida, México \\ 4 Facultad de Medicina, Universidad Autónoma de Yucatán, Mérida, México \\ 5 Doctorado en Ciencias Agropecuarias, Campus de Ciencias Biológicas y Agropecuarias, Universidad Autónoma \\ de Yucatán, Mérida, México
}

Introducción. La leptospirosis es una enfermedad zoonótica endémica en México, ocasionada por la bacteria del género Leptospira, la cual constituye un problema de salud pública y veterinaria. Los roedores son los reservorios más relevantes de Leptospira spp., debido a que la bacteria se establece y se reproduce en su tejido renal y es excretada por la orina.

Objetivo. Identificar la presencia de Leptospira spp. en tejido renal de roedores capturados en Yucatán, México.

Materiales y métodos. Se capturaron roedores sinantrópicos y silvestres en el municipio rural de Cenotillo, Yucatán, México. Se tomó un riñón de cada roedor y se extrajo el ADN total. La identificación de Leptospira spp. se hizo mediante la detección de dos fragmentos del gen 16S rRNA con una reacción en cadena de la polimerasa (PCR) de punto final. Los productos positivos se secuenciaron y se analizaron con herramientas de alineamiento.

Resultados. Se capturaron 92 roedores pertenecientes a siete especies distintas. La PCR arrojó $5,4 \%(5 / 92)$ de positividad global. El análisis del alineamiento de los aislamientos de los roedores infectados demostró $100 \%$ de cobertura e identidad con la especie Leptospira interrogans. Esta es la primera evidencia molecular de la circulación de Leptospira spp. en Heteromys gaumeri capturados en Yucatán, México.

Conclusión. Se evidenció que los roedores de Yucatán, México, son reservorios de Leptospira spp. y participan en el ciclo de infección de la leptospirosis en la región.

Palabras clave: Leptospira spp.; roedores; enfermedades de los roedores; México.

https://doi.org/10.7705/biomedica.v38i3.3938

\section{Molecular detection of pathogenic Leptospira in synanthropic and wild rodents captured in Yucatán, México}

Introduction: Leptospirosis is a zoonotic disease caused by bacteria of the genus Leptospira, which is endemic in México and considered a public and veterinary health problem. Rodents are the most relevant reservoirs of Leptospira spp. because the bacteria establish and reproduce in its renal tissue and are excreted through the urine.

Objective: To identify the presence of Leptospira spp. in renal tissue from rodents captured in Yucatán, México.

Materials and methods: Synanthropic and wild rodents were captured in the rural municipality of Cenotillo, Yucatán, México. We collected one kidney from each rodent and extracted the total DNA.

\footnotetext{
Contribución de los autores:

Marco Torres-Castro: dirección del estudio, captura de roedores, toma de muestras biológicas y escritura del manuscrito

Bayron Cruz Camargo, Bibiana Reyes-Hernández, Carlos Moguel-Lehmer, Armando López-Ávila y Henry Noh-Pech: diagnóstico de laboratorio e interpretación de resultados

Bayron Cruz-Camargo, Rodrigo Medina-Pinto, Rolando Medina, José Ortiz-Esquivel y William Arcila-Fuentes: captura de roedores y toma de muestras biológicas

Alonso Panti-May: interpretación de resultados y análisis de secuencias

Iván Rodríguez-Vivas y Fernando I. Puerto: coordinación general de actividades

Todos los autores revisaron la versión final del manuscrito.
} 
The identification of Leptospira spp. was done by detecting two fragments of the 16S rRNA gene using end-point polymerase chain reaction (PCR). We sequenced and analyzed positive products using alignment tools.

Results: A total of 92 rodents belonging to seven different species were captured. The PCR yielded a global positivity of $5.4 \%(5 / 92)$. The alignment analysis of the sequenced products demonstrated a $100 \%$ of coverage and identity with Leptospira interrogans. This is the first molecular evidence of Leptospira spp. circulation in Heteromys gaumeri captured in Yucatán, México.

Conclusion: Our results evidenced that rodents of Yucatán are reservoirs of Leptospira spp. and participate in the infection cycle of leptospirosis in the region.

Key words: Leptospira spp.; rodents; rodent diseases; México.

https://doi.org/10.7705/biomedica.v38i3.3938

La leptospirosis es una enfermedad zoonótica de distribución mundial, ocasionada por bacterias espiroquetas patógenas pertenecientes al orden Spirochaetales, familia Leptospiraceae, género Leptospira. Se dividen en 22 especies clasificadas en tres grupos: patógenas, intermedias y saprófitas o de vida libre, de las cuales las patógenas e intermedias tienen mayor importancia debido a su capacidad de ocasionar desde una amplia gama de signos o síntomas clínicos similares a los de un resfriado común, hasta un daño funcional multiorgánico y la muerte $(1,2)$.

La enfermedad es más frecuente en regiones con climas tropicales o subtropicales, al igual que en zonas que presentan inundaciones o precarias condiciones higiénicas y sanitarias (3). La Organización Mundial de la Salud (OMS) ha clasificado la leptospirosis como una de las enfermedades reemergentes y desatendidas (4).

Diversos animales domésticos y silvestres, así como accidentalmente el humano, están involucrados en el ciclo de infección de la leptospirosis; sin embargo, los reservorios de mayor relevancia son los pequeños mamíferos silvestres o sinantrópicos pertenecientes al orden Rodentia (1). Estos animales constituyen la fuente de infección más importante para los humanos y otros huéspedes vertebrados sensibles, los cuales se infectan principalmente por el contacto directo o indirecto con orina de roedores que contenga leptospiras viables (2).

\footnotetext{
Correspondencia:

Marco Torres-Castro, Laboratorio de Enfermedades Emergentes y Reemergentes, Centro de Investigaciones Regionales "Dr. Hideyo Noguchi", Universidad Autónoma de Yucatán, Avenida Itzáes N $\mathrm{N}^{\circ} 409$ por calle 59, Col. Centro, Mérida, Yucatán, México, C.P. 97000

Teléfono: (999) 9245809 y (999) 9236120

antonio.torres@correo.uady.mx

Recibido: 29/06/17; aceptado: 21/02/18
}

En México la leptospirosis se cataloga como un problema de salud pública y veterinaria, reportándose distintas tasas de incidencia y prevalencia en todo el territorio nacional. La leptospirosis humana se ha reportado en 27 de los 32 estados que conforman el país, en los cuales los brotes se presentan de manera ocasional (4).

En estudios previos en Yucatán, se ha reportado que los roedores capturados en el peridomicilio son reservorios de leptospiras patógenas $(5,6)$. Asimismo, en otros animales silvestres, como las zarigüeyas (7), y en los domésticos, como cerdos, vacas y perros, la infección también se ha documentado $(8,9)$. Sin embargo, no se han hecho estudios en roedores silvestres de las áreas rurales de Yucatán, por lo que el objetivo de esta investigación fue determinar la circulación de Leptospira spp. en el tejido renal de roedores sinantrópicos y silvestres capturados en un ambiente urbano y en otro selvático de Yucatán empleando la reacción en cadena de la polimerasa (PCR) y el análisis de alineamiento.

\section{Materiales y métodos}

\section{Sitio de estudio}

El estudio se llevó a cabo en la comunidad rural de Cenotillo (paralelos $20^{\circ} 55^{\prime}$ y $21^{\circ} 09^{\prime}$ de latitud norte y los meridianos $88^{\circ} 26^{\prime}$ y $88^{\circ} 48^{\prime}$ de longitud oeste), ubicada al este de Yucatán y a 107 km de Mérida, capital del Estado. Cuenta con una población de 3.701 habitantes, repartidos en casas construidas con materiales duraderos y perecederos, como piedra, cartón, lámina, madera y paja. El clima de la región es cálido subhúmedo, con una temperatura media anual de $26,3{ }^{\circ} \mathrm{C}$. La precipitación promedio anual es de $1.200 \mathrm{~mm}$, y las lluvias se presentan generalmente en los meses de mayo y julio (10).

El suelo es principalmente para uso agropecuario (agricultura y ganadería) y, menos frecuentemente, para asentamientos urbanos. La vegetación predominante en las zonas aledañas a la localidad 
es de selva baja caducifolia, con pequeñas extensiones de selva mediana subperennifolia en la que se observan parches de pasto forrajero. La fauna endémica está constituida por pequeños mamíferos como roedores, ardillas, mapaches, coatíes y tejones, así como diversas clases de reptiles y aves (10).

En la comunidad de estudio se pudieron observar numerosos perros y gatos deambulando en los predios y las calles, así como grandes cantidades de desechos orgánicos e inorgánicos.

\section{Captura de roedores}

Los roedores fueron capturados entre julio y noviembre de 2016 en viviendas de la localidad de estudio (sinantrópicos) y en extensiones de los parches de selva sin intervención antropogénica (silvestres) ubicadas a $9 \mathrm{~km}$ del sitio de estudio. El muestreo se hizo siguiendo los lineamientos de la American Society of Mammalogists (ASM) (11) y otras especificaciones nacionales (12).

Para la captura de los roedores sinantrópicos, el asentamiento urbano se dividió en cuatro cuadrantes trazando dos ejes perpendiculares en el centro de la población. En cada cuadrante se seleccionaron por conveniencia diez casas (40 en total) y, allí, se recogieron las muestras en dos noches consecutivas durante dos semanas de cada mes. En cada vivienda se colocaron doce trampas Sherman $(8 \times 9 \times 23 \mathrm{~cm}$; H.B. Sherman Traps Inc. TM; Tallahassee, Florida, Estados Unidos), distribuidas en el interior y en el patio, ubicadas cerca de lugares con evidencia de actividad o presencia de roedores y de potenciales fuentes de alimentación o alojamiento, previo consentimiento de los dueños u ocupantes.

Para el muestreo de las extensiones de selva, se distribuyeron 100 trampas Sherman a lo largo de diez transectos lineales, poniendo una trampa cada 8 a 9 metros. La captura se hizo en los mismos días y semanas que en los cuadrantes urbanos. Todas las trampas empleadas se colocaron en la mañana y se revisaron 24 horas después. El cebo utilizado fue una mezcla de hojuelas de avena y saborizante artificial de vainilla.

El presente estudio contó con la aprobación del Comité de Bioética del Campus de Ciencias Biológicas y Agropecuarias de la Universidad Autónoma de Yucatán (clave de registro: CBCCBA-M-2016-004) y de la Secretaría de Medio Ambiente y Recursos Naturales (registro $\mathrm{N}^{\circ}$ SGPA/DGVS/00867/17) de México.

\section{Toma de muestras biológicas}

Todos los roedores capturados fueron trasladados a una estación de campo habilitada para su procesamiento. Los animales fueron anestesiados con una inyección intraperitoneal de pentobarbital sódico $(130 \mathrm{mg} / \mathrm{kg}$ ) y se les practicó la eutanasia por dislocación cervical, según los lineamientos de la American Veterinary Medical Association (13).

Después de la eutanasia, se registraron los datos somáticos, la especie, el sexo, la edad (en ratones subadultos: $\leq 8 \mathrm{~g}$, en adultos: $>8 \mathrm{~g}$; en ratas subadultas: $\leq 66 \mathrm{~g}$, en adultas: $>66 \mathrm{~g}$ ) y el estado reproductivo de todos los individuos, el cual se consideró como "maduro" en hembras gestantes (embriones visibles), lactantes, o en las que tenían el orificio vaginal abierto, y como "inmaduro" cuando el orificio vaginal estaba cerrado. En machos, el estado "maduro" se determinó por la presencia de testículos no descendidos.

La identificación de las especies estuvo a cargo de médicos veterinarios con experiencia en muestreos y estudios poblacionales de roedores en la península de Yucatán. Además, se hicieron necropsias para recolectar las muestras biológicas (riñones), las cuales se depositaron en tubos para microcentrífuga de $1,5 \mathrm{ml}$ (Eppendorf ${ }^{\mathrm{TM}}$; Hamburgo, Alemania) embebidos en alcohol al $96 \%$ y conservados a $-70{ }^{\circ} \mathrm{C}$, hasta su empleo en la extracción del ADN total (hebra molde). Para evitar contaminaciones cruzadas, todo el instrumental empleado en la toma de muestras fue previamente desinfectado con alcohol y cloruro de benzalconio al $10 \%$.

\section{Extracción del ADN total e identificación molecular de Leptospira spp.}

Antes de la extracción de los ácidos nucleicos, los riñones se lavaron con agua bidestilada durante cinco minutos, aproximadamente, para retirar el exceso de alcohol. El ADN total se extrajo directamente del tejido renal con ayuda del estuche QIAamp DNA Mini Kit TM (QIAGEN; Hilden, Alemania), siguiendo el protocolo DNA Purification from Tissues y según las especificaciones del fabricante.

Todas las extracciones se hicieron en una campana de flujo laminar (Labconco ${ }^{\mathrm{TM}}$; Kansas City, Estados Unidos). Para la cuantificación y la evaluación del ADN total extraído, se empleó un espectrofotómetro (NanoDrop 2000 ${ }^{\mathrm{TM}}$, ThermoScientific, Wilmington, Estados Unidos). La hebra molde de ADN se conservó a $-70{ }^{\circ} \mathrm{C}$ hasta su empleo en la reacción molecular. 
La detección molecular de Leptospira spp. se hizo mediante dos PCR de punto final, según la metodología de Torres-Castro, et al. (5,6). En la primera reacción, la cual se utilizó en todas las extracciones de ADN, se usaron los oligonucleótidos 16S3 (sentido) (14) y 16SR (antisentido) (15), que amplifican un fragmento esperado de 150 pb perteneciente al gen $16 \mathrm{~S}$ ribosómico de Leptospira spp. (16S rRNA).

Con el objetivo de corroborar los resultados positivos de la reacción anterior, se hizo una segunda PCR en la cual se sustituyó el oligonucleótido $16 \mathrm{~S} 3$ con el 16S5 (sentido) (14) y se conservó el oligonucleótido 16SR (antisentido) (15), los cuales amplifican un tamaño aproximado de $1.004 \mathrm{pb}$ perteneciente también al gen 16SrRNA. Este gen es el más empleado y aceptado para el estudio y la identificación molecular de leptospiras patógenas y se encuentra muy conservado en todas las especies (patógenas, intermedias y saprófitas) (16).

Los reactivos utilizados en ambas reacciones tuvieron las siguientes concentraciones finales: solución tampón de PCR $5 \mathrm{X} ; 2,5 \mathrm{mM}$ de $\mathrm{MgCl}^{2}$; $0,2 \mathrm{mM}$ de deoxinucleósido trifosfato (dNTP); $0,2 \mathrm{mM}$ de cada cebador; $1 \mathrm{U}$ de Taq polimerasa (ThermoScientific Inc.; Massachusetts, Estados Unidos) y agua bidestilada cbp. Se emplearon 4 $\mathrm{ml}$ de hebra molde de ADN para un volumen final de $25 \mathrm{ml}$.

Las condiciones en el termociclador para ambas reacciones fueron las siguientes: un ciclo de desnaturalización inicial a $95{ }^{\circ} \mathrm{C}$ durante cinco minutos, seguido de 34 ciclos a $94{ }^{\circ} \mathrm{C}$ durante 45 segundos, $94^{\circ} \mathrm{C}$ durante un minuto y $72{ }^{\circ} \mathrm{C}$ durante dos minutos; la extensión final fue a $72{ }^{\circ} \mathrm{C}$ durante cinco minutos.

Para todas las reacciones, se incluyeron un control positivo (extracción de ADN de un cultivo de Leptospira patógena donado por el Laboratorio de Enfermedades Infecciosas y Parasitarias de la Facultad de Medicina, Universidad Autónoma de Yucatán) y un control negativo (agua estéril). La electroforesis de los productos de la PCR se hicieron en geles de agarosa al $1 \%$ teñidos con bromuro de etidio, y se visualizaron en un fotodocumentador (Bio-Rad; California, Estados Unidos).

\section{Purificación y análisis del alineamiento}

Los productos amplificados de 150 pb (correspondientes a la primera reacción) se retiraron del gel de agarosa al $1 \%$ con ayuda de un bisturí estéril $y$, posteriormente, se purificaron con el estuche comercial Zymoclean Gel DNA Recovery ${ }^{\mathrm{TM}}$ (ZymoResearch; California, Estados Unidos), según las especificaciones del fabricante. Los cinco productos purificados fueron enviados para su secuenciación al laboratorio DIMYGEN'TM (Mérida, Yucatán, México; http://www.dimygen.com/). Las secuencias obtenidas se compararon con otras previamente depositadas en el GenBank, empleando la herramienta Basic Local Alignment Search Tool (BLAST) del National Institutes of Heatlh (http://blast.ncbi. nlm.nih.gov/Blast.cgi), con el fin de determinar y comparar su identidad y similitud.

\section{Resultados \\ Captura de roedores}

Se capturaron 92 individuos pertenecientes a siete especies distintas: 25 (27,2 \%) Rattus rattus, 25 $(27,2 \%)$ Mus musculus, $22(23,9 \%)$ H. gaumeri, 10 (10,9\%) Ototylomys phyllotis, 8 (8,8 \%) Peromyscus yucatanicus, 1 (1,0\%) Peromyscus leucopus y $1(1,0 \%)$ Sigmodon hispidus. En el medio urbano se capturaron $48(52,2 \%)$ roedores: $24(50 \%)$ M. musculus y $24(50 \%)$ R. rattus, en tanto que, en el medio silvestre, se capturaron 44 (47,8 \%): 22 (50\%) H. gaumeri, $10(22,7 \%)$ O. phyllotis, $8(18,1 \%)$ P. yucatanicus, 1 (2,3\%) $P$. leucopus, $1(2,3 \%)$ S. hispidus, 1 (2,3\%) $R$. rattus y $1(2,3 \%) M$. musculus. Las frecuencias de las edades, sexos y estados reproductivos de los individuos pertenecientes a cada especie, se presentan en el cuadro 1.

\section{Identificación molecular de Leptospira spp.}

La prueba molecular arrojó una frecuencia positiva global de 5,4\% (5/92). De este porcentaje, 2 de 5 correspondió a $R$. rattus, otros 2 de 5 a $M$. musculus y 1 de 5 a $H$. gaumeri. Cuatro de 5 de los individuos positivos eran hembras y 1 de 5 era macho. Todos los roedores positivos eran adultos. En la figura 1 se muestra el gel representativo con algunos de los productos de PCR positivos. La frecuencia de infección por especie fue de $8 \%(2 / 25)$ para $R$. rattus, $8 \%(2 / 25)$ para $M$. musculus y $4,5 \%(1 / 22)$ para $H$. gaumeri.

\section{Análisis de alineamiento}

El análisis de alineamiento con la herramienta BLAST arrojó coberturas e identidades del $100 \%$ con respecto a la especie patógena $L$. interrogans, las cuales resultaron cercanas a los serovares Copenhageni, Canicola e Icterohaemorragiae. 
Cuadro 1. Número y frecuencias correspondientes a sexo, edad y estado reproductivo de los roedores sinantrópicos y silvestres capturados en la comunidad rural de Cenotillo, Yucatán, México

\begin{tabular}{|c|c|c|c|c|c|c|}
\hline \multirow[t]{2}{*}{ Especie } & \multicolumn{2}{|c|}{ Sexo } & \multicolumn{2}{|c|}{ Edad } & \multicolumn{2}{|c|}{ Estado reproductivo } \\
\hline & $\begin{array}{c}\text { Hembra } \\
\text { n (\%) }\end{array}$ & $\begin{array}{c}\text { Macho } \\
\text { n (\%) }\end{array}$ & $\begin{array}{c}\text { Subadulto } \\
\text { n (\%) }\end{array}$ & $\begin{array}{c}\text { Adulto } \\
\text { n (\%) }\end{array}$ & $\begin{array}{c}\text { Inmaduro } \\
\mathrm{n}(\%)\end{array}$ & $\begin{array}{c}\text { Maduro } \\
\text { n (\%) }\end{array}$ \\
\hline Rattus rattus & $18(19,6)$ & $7 \quad(7,6)$ & $4(4,3)$ & $21(22,9)$ & $4(4,3)$ & $21(22,9)$ \\
\hline Mus musculus & $11(12)$ & $14(15,2)$ & $14(15,2)$ & $11(12)$ & $14(15,2)$ & $11(12)$ \\
\hline Heteromys gaumeri & $14(15,2)$ & $8(8,7)$ & $10(10,9)$ & $12(13)$ & $10(10,9)$ & $12(13)$ \\
\hline Ototylomys phyllotis & $5(5,4)$ & $5 \quad(5,4)$ & $1(1,1)$ & $9(9,8)$ & $1(1,1)$ & $9(9,8)$ \\
\hline Peromyscus yucatanicus & $6(6,5)$ & $2 \quad(2,2)$ & $4(4,3)$ & $4 \quad(4,3)$ & $4(4,3)$ & $4(4,3)$ \\
\hline Peromyscus leucopus & $1 \quad(1,1)$ & $0 \quad(0)$ & $1(1,1)$ & $0 \quad(0)$ & $1 \quad(1,1)$ & $0 \quad(0)$ \\
\hline Sigmodon hispidus & $1 \quad(1,1)$ & $0 \quad(0)$ & $0 \quad(0)$ & $1 \quad(1,1)$ & $0 \quad(0)$ & $1(1,1)$ \\
\hline Total (\%) & $56(60,9)$ & $36(39,1)$ & $34(36,9)$ & $58(63,1)$ & $58(36,9)$ & $34(63,1)$ \\
\hline
\end{tabular}

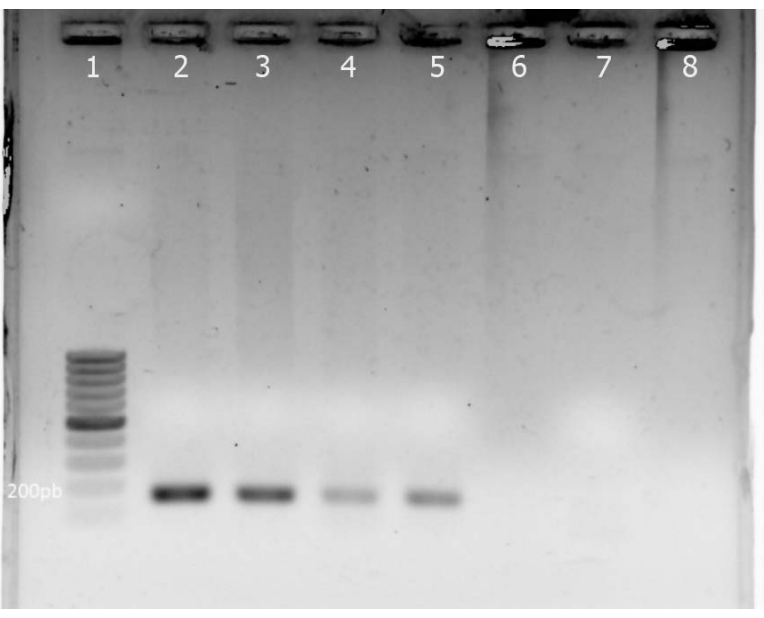

Figura 1. Gel de agarosa al $1 \%$ teñido con bromuro de etidio. Se observan algunas amplificaciones de 150 pb positivas para el gen 16S rRNA de Leptospira interrogans en roedores sinantrópicos y silvestres de Yucatán, México.

1: marcador de peso molecular de $100 \mathrm{pb}$; 2: muestra positiva de $H$. gaumeri; 3: muestra positiva de $R$. rattus; 4: muestra positiva de $M$. musculus; 5 : control positivo; 6 : control negativo; 7 y 8 : vacíos.

\section{Discusión}

En años recientes, se ha presentado en Yucatán un incremento significativo en el número de investigaciones epidemiológicas sobre agentes infecciosos con importancia en salud pública y veterinaria, en las que se ha establecido que los roedores sinantrópicos y silvestres son reservorios o portadores asintomáticos (17). Asimismo, en estudios poblacionales y ecológicos se ha comprobado que las especies sinantrópicas $M$. musculus y $R$. rattus son las más importantes y abundantes en ambientes urbanos y periurbanos de Yucatán, lo cual se debe a factores como la presencia de numerosas fuentes de alimento y de amplios sitios de resguardo y reproducción, así como al escaso número de depredadores $(18,19)$.
La circulación de Leptospira spp. se ha evidenciado en humanos (20-22) y en animales de Yucatán $(8,9,21,23)$, lo cual indica la importancia de esta bacteria en la región. De igual forma, Torres-Castro, et al. $(5,6)$, y Vado-Solís, et al. (21), demostraron la infección en $M$. musculus y $R$. rattus con especies y serovares patógenos de Leptospira spp. mediante pruebas moleculares, histopatológicas y serológicas. No obstante, Reyes-Novelo, et al. (24), han señalado la necesidad de incrementar el número de investigaciones en poblaciones de animales silvestres que pudieran estar involucrados en el ciclo infeccioso de la leptospirosis en el sureste de México.

El presente es el primer estudio realizado en siete especies de roedores silvestres y sinantrópicos de Yucatán. Actualmente, se reconoce que la fauna silvestre, particularmente los pequeños mamíferos, pueden considerarse reservorios de Leptospira spp. de origen silvestre, constituir una fuente de mantenimiento y potencial foco de infección interespecífica, asegurando la circulación de ciertos serovares entre las mismas especies de animales, y ser huéspedes sensibles a la infección cuando entran en contacto por primera vez con serovares de circulación doméstica con los cuales no habían tenido contacto en su ambiente silvestre natural. Asimismo, se ha descrito que los animales silvestres pueden convertirse en huéspedes de mantenimiento, dependiendo de elementos como el serovar infeccioso y los factores ambientales $(25,26)$, y representar un riesgo potencial para la diseminación de la enfermedad en las poblaciones humanas (2).

Heteromys gaumeri es un roedor endémico de la península de Yucatán, y ya se ha identificado en estudios en ambientes periurbanos y urbanos de la región (18,27). Espinosa-Martínez, et al. (28), demostraron la circulación de $L$. interrogans en 
un individuo capturado en la reserva ecológica de Calakmul, Campeche, México, hallazgo similar al reportado en la presente investigación. Ambos hallazgos aportan nueva evidencia sobre la probable participación de este roedor en el ciclo infeccioso de la leptospirosis; además, los presentes resultados los sitúan como nuevos reservorios de Leptospira spp. en Yucatán. En un estudio previo, Panti-May, et al. (27), reportaron individuos de $H$. gaumeri positivos para Rickettsia felis, otro patógeno zoonótico endémico en la región (29).

En numerosos estudios moleculares alrededor del mundo, se ha documentado la circulación de Leptospira spp. en roedores sinantrópicos, principalmente $R$. rattus y $M$. musculus, lo cual los convierte en los reservorios más relevantes de dicha bacteria (30). En algunos de estos estudios se han registrado frecuencias de infección superiores a la reportada en el presente trabajo; por ejemplo, Guernier, et al. (31), evidenciaron prevalencias de 38,5 y $9 \%$ para $R$. rattus y $M$. musculus, respectivamente, en la Isla Reunión. Asimismo, Halliday, et al. (32), encontraron $20 \%$ de infección en ejemplares de $M$. musculus y $9 \%$ en los de $R$. rattus capturados en un asentamiento urbano de Nairobi, Kenia.

En otros estudios se presentan porcentajes similares al descrito en el presente, por ejemplo, MayerScholl, et al. (33), encontraron $6 \%$ en individuos $M$. musculus capturados en 11 regiones de Alemania. En Tanzania, Mgode, et al. (34), no reportaron individuos $R$. rattus o M. musculus positivos, aunque debe señalarse que trabajaron con un ejemplar de cada especie.

Por otra parte, los productos aislados en las tres especies de roedores positivos en el presente estudio correspondieron a la especie patógena $L$. interrogans, previamente identificada en estos mismos animales en Yucatán (5). Asimismo, Foronda, et al. (35), reportaron la circulación de $L$. interrogans en $M$. musculus y $R$. rattus capturados en las Islas Canarias, España, y Tucunduva de Faria, et al. (36), en individuos Rattus spp., capturados en Salvador, Brasil.

En el presente estudio se registró una mayor frecuencia de infección en los roedores capturados en el ambiente urbano en comparación con los obtenidos en el medio silvestre, lo cual sugeriría que las leptospiras no se estarían propagando entre las poblaciones de roedores de ambos sitios de captura; sin embargo, se requieren nuevos estudios epidemiológicos para corroborar esta hipótesis.
Después de la confirmación de la presencia de Leptospira patógena en tejido renal de roedores sinantrópicos y silvestres de Yucatán, es necesario hacer muestreos más extensos y numerosos que ayuden a identificar otras especies, así como los serovares de Leptospira circulantes que eventualmente puedan infectar a animales y humanos de la región, pues la presencia de fauna silvestre o doméstica en las viviendas se ha asociado con la presentación de casos de leptospirosis humana de curso moderado a grave $(37,38)$.

Asimismo, deben hacerse capturas en diferentes estaciones y temporadas (de lluvia y secas), ya que el factor ambiental también puede influir en los porcentajes de positividad encontrados en las diferentes especies $(2,37)$, pues el contacto con fuentes de agua contaminada es un elemento fundamental para la transmisión de Leptospira spp. (39-42). Además, un estudio de casos y controles ayudaría a determinar el riesgo real asociado con la incidencia de leptospirosis en la población humana del sitio de estudio (43).

Resulta necesario aclarar las limitaciones del presente trabajo: aunque fue posible determinar que los roedores capturados eran portadores de Leptospira spp., y habían excretado bacterias viables, la técnica utilizada no permitió identificar los serovares involucrados en la infección, por lo que es necesario utilizar otras herramientas diagnósticas de identificación, como la microaglutinación (MAT), que permitan, además, saber si las posibles serovares son atípicos para los roedores de Yucatán $(44,45)$. La identificación de serovares de Leptospira spp. en ambientes endémicos permite un mejor conocimiento de la epidemiología de la enfermedad, así como la implementación de medidas de control durante posibles brotes (46).

En conclusión, los roedores capturados en el sitio de estudio (Yucatán, México) eran reservorios de Leptospira spp. y podrían ser parte del ciclo de infección de la leptospirosis en la región. Se presenta la primera evidencia molecular de la circulación de Leptospira spp. en H. gaumeri en Yucatán, México.

\section{Agradecimientos}

Expresamos nuestro sincero agradecimiento a las autoridades municipales y a las familias de Cenotillo, Yucatán, México, por permitirnos el ingreso a sus hogares para la captura de los roedores. Este trabajo fue realizado en parte por alumnos del proyecto "SAVIA" de la Secretaría de Investigación, Innovación y Educación Superior del Gobierno del Estado de Yucatán. 


\section{Conflicto de intereses}

Los autores declaran que no existe ningún conflicto de intereses para la publicación del presente manuscrito.

\section{Financiación}

La captura de roedores y la toma de muestras biológicas fueron financiadas por el proyecto Vector Borne Zoonosis in Yucatán: A One Health Approach, código FMVZ-2016-0007. El trabajo de laboratorio se financió con recursos internos del Laboratorio de Enfermedades Emergentes y Reemergentes del Centro de Investigaciones Regionales "Dr. Hideyo Noguchi", UADY.

\section{Referencias}

1. Ko Al, Goarant C, Picardeau M. Leptospira: The dawn of the molecular genetics era for emerging zoonotic pathogen. Nat Rev Microbiol. 2009;7:736-47. https://doi.org/10.1038/ nrmicro2208

2. Yalin W, Lingbing Z, Hongliang $Y$, Jianmin $X$, Xiangyan Z, Xiaokui G, et al. High prevalence of pathogenic Leptospira in wild and domesticated animals in an endemic area of China. Asian Pac J Trop Med. 2011;4:841-5. https://doi. org/10.1016/S1995-7645(11)60205-8

3. Torres-Castro M, Hernández-Betancourt S, AgudeloFlórez P, Arroyave-Sierra E, Zavala-Castro J, Puerto IF. Revisión actual de la epidemiología de la leptospirosis. Rev Med Inst Mex Seguro Soc. 2016;54:620-5.

4. Sánchez-Montes S, Espinosa-Martínez DV, Ríos-Muñoz CA, Berzunza-Cruz M, Becker I. Leptospirosis in Mexico: Epidemiology and potential distribution of human cases. PLoS One. 2015;10:e0133720. https://doi.org/10.1371/ journal.pone. 0133720

5. Torres-Castro MA, Gutiérrez-Ruiz E, HernándezBetancourt S, Peláez-Sánchez R, Agudelo-Flórez P, Guillermo-Cordero L, et al. First molecular evidence of Leptospira spp. in synanthropic rodents captured in Yucatán, México. Revue Méd Vét. 2014;165:213-8.

6. Torres-Castro M, Guillermo-Cordero L, HernándezBetancourt S, Gutiérrez-Ruiz E, Agudelo-Flórez P, Peláez-Sánchez R, et al. First histopathological study in kidneys of rodents naturally infected whit Leptospira pathogenic species from Yucatán, México. Asian Pac J Trop Med. 2016;9:145-7. https://doi.org/10.1016/j.apjtm. 2016.01.018

7. Ruiz-Piña HA, Puc-Franco MA, Flores-Abuxapqui J, Vado-Solis I, Cárdenas-Marrufo MF. Isolation of Salmonella enterica and serologic reactivity to Leptospira interrogans in opossums (Didelphis virginiana) from Yucatán, México. Rev Inst Med trop Sao Paulo. 2002;44:235-7. https://doi. org/10.1590/S0036-46652002000400011

8. Cárdenas-Marrufo MF, Vado-Solís I, Pérez-Osorio CE, Segura-Correa JC. Seropositivity to leptospirosis in domestic reservoirs and detection of Leptospira spp. from water sources, in farms of Yucatán, México. Trop Subtrop Agroecosyst. 2011;14:185-9.

9. Jiménez-Coello M, Vado-Solís I, Cárdenas-Marrufo MF, Rodríguez-Buenfil JC, Ortega-Pacheco A. Serological survey of canine leptospirosis in the tropics of Yucatán, México, using two different tests. Acta Trop. 2008;106:22-6. https://doi.org/10.1016/j.actatropica.2007.12.011

10. Enciclopedia de los Municipios y Delegaciones de México. Estado de Yucatán. Fecha de consulta: 10 de enero de 2017. Disponible en: http://www.inafed.gob.mx/ work/enciclopedia/EMM31yucatan/municipios/31012a.html

11. Sikes RS, Gannon WL, Animal Care and Use Committee of the American Society of Mammalogists. Guidelines of the American Society of Mammalogists for the use of wild mammals in research. J Mammal. 2011;92:235-53. https:// doi.org/10.1644/10-MAMM-F-355.1

12. Norma Oficial Mexicana NOM.062-ZOO-1999. Especificaciones técnicas para la producción, cuidado y uso de los animales de laboratorio. Diario Oficial de la Federación. México. Fecha de consulta: 10 de enero de 2017. Disponible en: http://www.ibt.unam.mx/computo/pdfs/bioterio. NOM-062.pdf

13. Leary S, Underwood W, Lilly E, Anthony R, Cartner $\mathbf{S}$, Corey $\mathbf{S}$, et al. AVMA guidelines for the euthanasia of animals. Schaumburg, Illinois: American Veterinary Medical Association; 2013. p. 18-41.

14. Haake DA, Suchard MA, Kelley MM, Dundoo M, Alt DP, Zuerner RL. Molecular evolution and mosaicism of leptospiral outer membrane proteins involves horizontal DNA transfer. J Bacteriol. 2004;186:2818-28. https://doi. org/10.1128/JB.186.9.2818-2828.2004

15. Shukla J. $16 \mathrm{~S}$ rRNA PCR for differentiation of pathogenic and non-pathogenic leptospira isolates. Indian $\mathrm{J}$ Med Microbiol. 2003;21:25-30.

16. Backstedt BT, Buyuktanir O, Lindow J, Wunder EA Jr, Reis MG, Usmani-Brown S, et al. Efficient detection of pathogenic leptospires using 16S ribosomal RNA. PLoS One. 2015;10:e0128913. https://doi.org/10.1371/journal. pone.0128913

17. Torres-Castro M. Estudio sobre roedores sinantrópicos como reservorios de patógenos zoonóticos en Yucatán. Rev Biomed. 2017;28:89-115.

18. Panti-May A, Hernández-Betancourt $\mathbf{S}$, Ruiz-Piña $\mathbf{H}$, Medina-Peralta S. Abundance and population parameters of commensal rodents present in rural households in Yucatán, México. Int Biodeter Biodegr. 2012;66:77-81. https://doi.org/10.1016/j.ibiod.2011.10.006

19. Panti-May JA, Hernández-Betancourt SF, Torres-Castro MA, Machain-Williams C, Cigarroa-Toledo N, Sodá L, et al. Population characteristics of human-commensal rodents present in households from Mérida, Yucatán, México. Manter (Linc). 2016. Fecha de consulta: 10 de enero de 2017. Disponible en: https://digitalcommons.unl.edu/ parasitology-manterlab/

20. Zavala-Velázquez JE, Vado-Solís IA, Rodríguez-Félix ME, Rodríguez-Angulo EM, Barrera-Pérez MA, GuzmánMarín ES. Leptospirosis anictérica en un brote epidémico de dengue en la península de Yucatán. Rev Biomed. 1998; 9:78-83.

21. Vado-Solís I, Cárdenas-Marrufo MF, Jiménez-Delgadillo $B$, Alzina-López A, Laviada-Molina $\mathrm{H}$, Suárez-Solís $\mathrm{V}$, et al. Clinical-epidemiological study of leptospirosis in humans and reservoirs in Yucatán, México. Rev Inst Med Trop Sao Paulo. 2002;44:335-40. https://doi.org/10.1590/S0036-4665 2002000600008 
22. Zavala-Velázquez J, Cárdenas-Marrufo $M$, Vado-Solís I, Cetina-Cámara M, Cano-Tur J, Laviada-Molina $\mathrm{H}$. Hemorrhagic pulmonary leptospirosis: Three cases from the Yucatán peninsula, México. Rev Soc Bras Med Trop. 2008;41:404-8. https://doi.org/10.1590/S0037-8682200800 0400016

23. Ortega-Pacheco A, Colin-Flores RF, Gutiérrez-Blanco $\mathbf{E}$, Jiménez-Coello $\mathbf{M}$. Frequency and type of renal lesions in dogs naturally infected with Leptospira species. Ann N Y Acad Sci. 2008;1149:270-274. https://doi.org/10.1196/ annals. 1428.088

24. Reyes-Novelo E, Ruiz-Piña H, Escobedo-Ortegón J, Rodríguez-Vivas I, Bolio-González M, Polanco-Rodríguez Á, et al. Situación actual y perspectivas para el estudio de las enfermedades zoonóticas emergentes y reemergentes y olvidadas de la península de Yucatán, México. Trop Subtrop Agroecosys. 2011;14:35-54.

25. Lilenbaum W, Monteiro RV, Albuquerque CE, Ristow $\mathbf{P}$, Fraguas S, Cardoso VS, et al. Leptospiral antibodies in wild felines from Rio de Janeiro Zoo, Brazil. Vet J. 2004;168: 191-3. https://doi.org/10.1016/S1090-0233(03)00139-4

26. Vieira AS, Narduche L, Martins G, Schabib-Péres IAHF, Zimmermann NP, Juliano RS, et al. Detection of wild animals as carriers of Leptospira by PCR in the Panantal biome, Brazil. Acta Trop. 2016;163:87-9. https://doi.org/10. 1016/j.actatropica.2016.08.001

27. Panti-May JA, Torres-Castro M, Hernández-Betancourt S, Dzul-Rosado K, Zavala-Castro J, López-Ávila K, et al. Detection of Rickettsia felis in wild mammals from three municipalities in Yucatán, México. Ecohealth. 2015;12:5237. https://doi.org/10.1007/s10393-014-1003-2

28. Espinosa-Martínez DV, Sánchez-Montes DS, LeónPaniagua L, Ríos-Muñoz CA, Berzunza-Cruz M, Becker I. New wildlife hosts of Leptospira interrogans in Campeche, México. Rev Inst Med Trop Sao Paulo. 2015;57:181-3. https://doi.org/10.1590/S0036-46652015000200015

29. Zavala-Castro J, Zavala-Velázquez J, Walker D, PérezOsorio J, Peniche-Lara G. Severe human infection with Rickettsia felis associated with hepatitis in Yucatán, México. Int J Med Microbiol. 2009;299:529-33. https://doi. org/10.1016/j.jmm.2009.03.002

30. Desvars A, Naze F, Benneveau A, Cardinale E, Michault A. Endemicity of leptospirosis in domestic and wild animal species from Reunion Island (Indian Ocean). Edemiol Infect. 2013;141:1154-65. https://doi.org/10.1017/ S0950268812002075

31. Guernier V, Lagadec E, Cordonin C, Le Minter G, Gomard Y, Pagès $F$, et al. Human leptospirosis on Reunion Island, Indian Ocean: Are rodents the (only) ones to blame? PLoS Negl Trop Dis. 2016;10:e0004733. https://doi.org/10.1371/ journal.pntd.0004733

32. Halliday JE, Knobel DL, Allan KJ, de C Bronsvoort BM, Handel I, Agwanda B, et al. Urban leptospirosis in Africa: A cross-sectional survey of Leptospira infection in rodents in the Kibera urban settlement, Nairobi, Kenya. Am J Trop Med Hyg. 2013;89:1095-102. https://doi.org/10.4269/ajtmh. $13-0415$

33. Mayer-Scholl A, Hammerl JA, Schmidt S, Ulrich RG, Pfeffer M, Woll D, et al. Leptospira spp. in rodents and shrews in Germany. Int J Environ Res Public Health. 2014; 11:7562-74. https://doi.org/10.3390/ijerph110807562
34. Mgode GF, Mhamphil G, Katakweba A, Paemelaere E, Willekens $\mathbf{N}$, Leirs $\mathbf{H}$, et al. PCR detection of Leptospira DNA in rodents and insectivores from Tanzania. Belg $\mathrm{J} \mathrm{Zool.}$ 2005; 135:17-9.

35. Foronda P, Martín-Alonso A, Del Castillo-Figueruelo B, Feliu C, Gil H, Valladares B. Pathogenic Leptospira spp. in wild rodents, Canary Islands, Spain. Emerg Infect Dis. 2011;17:1781-2. https://doi.org/10.3201/eid1709.101470

36. De Faria MT, Calderwood MS, Athanazio DA, McBride AJ, Hartskeerl RA, Pereira MM, et al. Carriage of Leptospira interrogans among domestic rats from and urban setting highly endemic for leptospirosis in Brazil. Acta Trop. 2008;108:1-5. https://doi.org/10.1016/j.actatropica.2008. 07.005

37. Yusti D, Arboleda M, Agudelo-Flórez P. Factores de riesgo sociales y ambientales relacionados con casos de leptospirosis de manejo ambulatorio y hospitalario, Turbo, Colombia. Biomédica. 2013;33:117-29. https://doi. org/10.7705/biomedica.v33i0.1457

38. Shelotto F, Hernández E, González S, Del Monte A, Ifran S, Flores $\mathrm{K}$, et al. A ten-year follow-up of human leptospirosis in Uruguay: An unresolved health problem. Rev Inst Med Trop Sao Paulo. 2012;54:69-75. https://doi. org/10.1590/S0036-46652012000200003

39. Loan HK, van Cuong N, Takhampunya $R$, Kiet BT, Campbell J, Them LN, et al. How important are rats as vectors of leptospirosis in the Mekong Delta of Vietnam? Vector Borne Zoonotic Dis. 2015;15:56-65. https://doi. org/10.1089/vbz.2014.1613

40. Scialfa E, Bolpe J, Bardón JC, Ridao G, Gentile J, Gallicchio 0 . Isolation of Leptospira interrogans from suburban rats in Tandii, Buenos Aires, Argentina. Rev Argent Microbiol. 2010;42:126-128. https://doi.org/10.1590/ S0325-75412010000200012

41. Verdasquera-Corcho D, Barroso-Corría J, BarrerasSuárez BA, Pérez-Rodríguez A, Pérez-Soler K, ObregónFuentes AM, et al. Factores asociados a la morbilidad por leptospirosis humana. Ciudad de La Habana, 2005-2006. Rev Panam Infectol. 2010;12:8-16.

42. Nájera S, Alvis N, Babilonia D, Álvarez L, Máttar S. Leptospirosis ocupacional en una región del Caribe colombiano. Salud Públ Méx. 2005;47:240-4.

43. Agudelo-Flórez P, Londoño AF, Quiroz VH, Ángel JC, Moreno N, Loaiza ET, et al. Prevalence of Leptospira spp. in urban rodents from a groceries trade center of Medellín, Colombia. Am J Trop Med Hyg. 2009;81:906-10. https://doi. org/10.4269/ajtmh.2009.09-0195

44. Treml F, Nepeřený J, Janová E, Band'ouchová H, Pikula J. Prevalence of antibodies against leptospires in small mammals in relation to age, sex and season. ActaVer Brno. 2012;81:1097-102. https://doi.org/10.2754/ avb201281020097

45. Bharti AR, Nally JE, Ricaldi JN, Matthias MA, Díaz MM, Lovett MA, et al. Leptospirosis: A zoonotic disease of global importance. Lancet Infect Dis. 2003;3:757-71. https://doi.org/10.1016/S1473-3099(03)00830-2

46. Romero-Vivas CM, Thiry D, Rodríguez V, Calderón A, Arrieta G, Máttar S, et al. Molecular serovar characterization of Leptospira isolates from animals and water in Colombia. Biomédica. 2013;33:179-184. https://doi.org/10. 7705/biomedica.v33i0.731 